\title{
Effects of the thickness of cross-laminated timber (CLT) panels made from Irish Sitka Spruce on mechanical performance in bending and shear
}

\author{
Karol S Sikora ${ }^{1}$, Daniel O McPolin ${ }^{2}$, Annette M Harte $^{1^{*}}$ \\ ${ }^{1}$ National University of Ireland, Galway, University Road, Galway, Ireland, e-mails: karol.sikora@nuigalway.ie, annette.harte@nuigalway.ie \\ 2 Queen's University Belfast, University Road, Belfast, BT7 1NN, UK, email: d.mcpolin@qub.ac.uk
}

\begin{abstract}
An investigation was carried out on CLT panels made from Sitka spruce in order to establish the effect of the thickness of CLT panels on the bending stiffness and strength and the rolling shear. Bending and shear tests on 3-layer and 5-layer panels were performed with loading in the out-of-plane and in-plane directions. 'Global' stiffness measurements were found to correlate well with theoretical values. Based on the results, there was a general tendency that both the bending strength and rolling shear decreased with panel thickness. Mean values for rolling shear ranged from $1.0 \mathrm{~N} / \mathrm{mm}^{2}$ to $2.0 \mathrm{~N} / \mathrm{mm}^{2}$.
\end{abstract}

\section{Highlights}

- The thicker the CLT panel is, the lower its bending and rolling shear strengths.

- Rolling shear strength values for Sitka spruce of 1.0-2.0 N/mm².

- 'Global' deformation results closely match theoretical stiffness.

- Cross-lamination provides no strengthening effect for in-plane bending behaviour.

\section{Keywords}

Cross-laminated Timber (CLT), Engineered wood, Mechanical performance, Modulus of Elasticity, Strength, Sitka spruce

\section{Introduction}

The construction industry has been undergoing continuous modification and improvement in order to successfully comply with the requirements of sustainable development, leading to a requirement for more durable, less labour- and service-intensive materials at a competitive price. One of the most promising materials meeting these requirements is 
cross-laminated timber (CLT). CLT is a prefabricated multi-layer engineered panel wood product, manufactured from at least three layers of parallel boards by gluing their surfaces together with an adhesive under pressure. The grain direction of consecutive layers is orientated orthogonally. The number of laminates in CLT is generally odd, therefore face layers are parallel to each other. This specific orientation results in excellent in-plane and out-of-plane strength, rigidity, and stability characteristics. The degree of anisotropy in properties and the influence of natural variations, such as knots, are reduced in comparison with construction timber [1-6]. Load-bearing CLT wall and floor panels are easily assembled on site to form multi-storey buildings, improving construction and project delivery time, reducing costs, and maximising efficiency on all levels [2, 7-9].

Many timber species for CLT production have been investigated worldwide. Fortune and Quenneville [6] aimed to establish the use of CLT in New Zealand using locally grown Radiata pine bonded using resorcinol adhesive. CLT panels were generally, but not always, stronger than their constituent boards. CLT material fabricated using Southern pine was tested in bending, by Hindman and Bouldin [10], to establish the bending strength, bending stiffness, and shear strength. These properties exceeded the published values for the V3 grade [11]. Furthermore, prototype Sugi CLT floor panels were manufactured by Okabe et al. [12] and bending tests were carried out for different numbers of layers and thickness of CLT panels. The bending stiffness calculated using composite theory and the Monte Carlo method was in agreement with the experimental bending stiffness. It was found that the moment carrying capacity calculated by the deterministic design method underestimated the moment carrying capacity of the CLT panels. Park et al. [13] investigated 30 types of 3ply parallel- and cross- laminated panels from five species (Sugi, Hinoki, Kiri, Katsura, and Buna). They found that the bending creep performance perpendicular to the grain was improved by cross-lamination. The effects of width and lay-up on the tensile strength of CLT were studied by Ido et al. [14]. The elastic modulus of CLT made of Sugi with different layups was measured by dynamic and static methods, and tensile tests were conducted for different widths and lay-ups. The results showed that the variations in lay-ups affected the CLT. The estimated tensile strength of CLT, as calculated using the Young's modulus of the lamina of each layer, and the tensile strength of lamina were found to be in good agreement with the measured tensile strength of CLT. Recently, Wang el al. [15] evaluated on mechanical behaviour of timber composites. Four types of CLT panels, one generic CLT (used as control) and three types of Hybrid cross-laminated timber (HCLT), using lumber and/or laminated strand lumber (LSL), were fabricated. It was found that the HCLT had better bending performance (MOE 13\%-19\% higher, MOR 24\%-36\% higher).

Park et al. [13] found that the experimentally obtained Modulus of Elasticity (MOE) parallel to the grain of the face laminate of CLT was much lower than the calculated MOE due to the effect of the deflection caused by shear force on the MOE. In addition, there was an extremely high positive correlation between the Modulus of Rupture (MOR) and the measured MOE parallel to the grain of the face laminate of CLT. Their findings are in line with the study by Niederwestberg \& Chui [16], who explored material and structural 
characteristics of laminates and their effects on the overall characteristics of CLT using modal testing and static testing. Comparing MOE values from the static tests with the values calculated by the shear analogy showed that the results from the static tests were about $50 \%$ lower than the calculated ones. This was explained by the high influence of shear deformation in bending tests with specimens with a span to thickness ratio of about 10 . Blass and Fellmoser [17] proposed that only for span-to-depth ratios of at least 30 could the influence of shear be disregarded for loading perpendicular to the plane. In another study Vessby et al. [5] investigated the structural performance of 5-layer cross-laminated timber elements, made of $19 \mathrm{~mm}$ thick C24 boards glued together with PUR adhesive. The stiffness and strength of four cross-laminated timber elements (4955 mm long, $1250 \mathrm{~mm}$ wide and $96 \mathrm{~mm}$ thick) were studied during in-plane bending. The results showed the CLT elements possess a high degree of stiffness and strength, and a significant difference in behaviour was found between the two different ways in which the elements were connected to each other. Furthermore, investigations of the effect of different CLT specimen sizes on the tests results were performed. Steiger and Gülzow [18], and Steiger et al. [19] assessed bending strength and stiffness of the CLT by 4-point bending tests of strip- shaped specimens with a width of $100 \mathrm{~mm}$, cut from the panels. For both parameters differences in strength and stiffness of up to $100 \%$ were found for strip-shaped specimens cut from the panels. This was attributed to local defects and non-homogeneities due to the quality of the raw material or due to the method of producing the panels as bending strength and stiffness of CLT panels can vary quite strongly within one single panel. Rolling shear failures, which frequently occurred when testing the $100 \mathrm{~mm}$ wide strip-shaped specimens, were not observed in destructive tests of gross CLT panels.

Cross layers in structural bonded timber elements loaded perpendicular to the plate show significant rolling shear deformations caused by the very low rolling shear stiffness of timber. Blass and Görlacher [20] established a characteristic value of $1.0 \mathrm{~N} / \mathrm{mm}^{2}$ for the rolling shear strength of European spruce, independent of the strength class. Their tests of different timber bonded elements confirmed the validity of the calculation model and verify the value for the rolling shear modulus of $50 \mathrm{~N} / \mathrm{mm}^{2}$ published by Neuhaus [21]. However, this value may differ slightly depending on certain wood properties such as density and annual ring orientation [17]. Zhou et al. [22] observed that cross layers with growth ring orientation in-between flat- and quarter-sawn could increase the rolling shear modulus in comparison to flat-sawn or quarter-sawn. In another study, Zhu et al. [36] indicated that the shear analogy method could be used to more accurately predict the deflection of a threelayer CLT specimen using the measured rolling shear modulus when the span-to-depth ratio was relatively small. Their CLT panels were made of Black spruce (Picea mariana) timber and fast-curing epoxy or one-component PUR. The average rolling shear strength of 3-layer down-scaled CLT was 2.74 MPa under 3-point bending tests at a span to depth ratio of 6 . Furthermore, Zhu et al. [23] suggest that the bending test might be the most appropriate test method for the determination of the shear strength of CLT because it can produce a rolling shear failure mode that is encountered under bending. Moreover, an extensive study 
by Li [24] showed that the mean rolling shear strength value ranges from $1.41 \mathrm{MPa}$ to 1.76 $\mathrm{MPa}$, and confirmed previous claims that the rolling shear strength is affected by specimen size, loading type and loading protocol. In another study, Saavedra Flores et al. [25] investigated the rolling shear failure in CLT fabricated with Chilean radiata pine bonded with Emulsion Polymer Isocyanate (EPI) adhesive. However, a very limited number of specimens were tested and the study focused on developing cohesive zone models to simulate the cracking in the material. These numerical predictions were in line with experimental results.

Even though the technology of CLT production and the theory of the mechanical behaviour of CLT are well understood [2, 26], there is still a lack of experimental data on the mechanical performance of CLT panels. Since a huge variety of wood species, even of low strength grades, confirmed potential for utilisation in CLT exists, further studies on using different timber species for CLT production should be carried out. One of the timber species with such potential is Irish-grown Sitka spruce, characterised as a fast growing, low density species due to the rapid growth conditions in Ireland and short rotation length. It is the most-widely grown species in Ireland, therefore its usage in construction, as a locally sourced material, would follow sustainable development trends [27]. Previous studies, which investigated the performance in bending, shear behaviour, and failure modes, confirmed its potential for production of engineered-wood products [28-36]. Furthermore, the mechanical behaviour of CLT panels made from Scottish Sitka spruce was investigated by Crawford et al. [37]. Two 3-layer and one 5-layer CLT panels were prefabricated using 40 x $95 \mathrm{~mm}$ Sitka Spruce boards, graded to C16, and polyurethane (PUR) adhesive. Established bending strengths and stiffnesses in in-plane and out-of-plane were not dissimilar to the commercially available CLT panels, manufactured in Central Europe, indicating the potential for utilisation of Sitka spruce in CLT. The main objectives of this study were to determine the strength and stiffness properties of CLT panels made from Sitka spruce (Picea sitchensis) and to establish the effects of the thickness of the CLT panels on the mechanical performance in bending. Therefore, CLT samples of a variety of sizes and thickness were manufactured using the technical data determined in an earlier investigation [38]. This investigation led to the establishment of the optimal production technology parameters for manufacturing CLT from Irish Sitka Spruce namely, the adhesive type, the spread rate, and the clamping pressure. For the purpose of this article, the established values were used during the manufacture of CLT panels for the structural performance assessment. Smaller 3-layer panels of two thicknesses were tested in bending with loads applied perpendicular to the plane direction on two different spans in order to determine bending and shear strengths and stiffness properties. Furthermore, larger 3-layer and 5-layer panels were tested in bending with loads applied in both in-plane and out-of-plane directions.

\section{Materials and methods}

\subsection{Materials}

Testing of strength and stiffness properties of CLT was carried out in accordance with prEN 16351 [39] for 10 different sizes and test configurations of CLT panels in order to determine the desired properties, as detailed in Table 1. For each test configuration, 3 replicates were 
tested. Boards of C16 Irish Sitka spruce (Picea sitchensis) of nominal cross-sectional dimensions of $100 \mathrm{~mm} \times 35 \mathrm{~mm}$ (for panels with layers of thickness below $40 \mathrm{~mm}$ ), and 150 $\mathrm{mm} \times 44 \mathrm{~mm}$ (for panels with layers of thickness of $40 \mathrm{~mm}$ ), used for CLT panels manufacture, were stored in a conditioning chamber $\left(65 \pm 5 \%\right.$ R.H., $\left.20 \pm 2^{\circ} \mathrm{C}\right)$ for 3 months before specimen preparation. The conditioned timber had a moisture content of approximately $12 \%$, which satisfies the manufacturers requirement that it be not less than $8 \%$. Prior to fabrication all sides of the boards were planed to the desired thicknesses (20 $\mathrm{mm}, 24 \mathrm{~mm}$, and $40 \mathrm{~mm}$ ), and widths ( $96 \mathrm{~mm}$ or $146 \mathrm{~mm}$ ). Also the natural frequency of each board was recorded using the Timber Grader MTG 860 in order to determine the MOE parallel to the wood grain direction, and a mean value of $8160 \mathrm{~N} / \mathrm{mm}^{2}$ was recorded. Furthermore, values of $437 \mathrm{~kg} / \mathrm{m}^{3}$ and $348 \mathrm{~kg} / \mathrm{m}^{3}$ for the mean and characteristic densities, respectively, were obtained for all timber used in accordance with EN 384 [40]. All panels were manufactured using one component PUR adhesive (PURBOND HB S309) with a spreading rate of $160 \mathrm{~g} / \mathrm{m}^{2}$, and a pressure (face bonding only, no edge bonding) of 0.6 $\mathrm{N} / \mathrm{mm}^{2}$ was applied for 120 minutes. The pressure was applied by a hydraulic press with a maximum capacity of $500 \mathrm{kN}$ for smaller panels, and using steel plates clamped using M20 steel bolts, which were tightened with a calibrated toque wrench to provide the required compressive force, for bigger panels. The total axial force from all of the bolts required to produce a clamping pressure of $0.6 \mathrm{MPa}$ varied with the panel size. Figure 1 shows manufacture of CLT panels using: (a) hydraulic press, (b) bolts and steel plates. The specimens were then reconditioned.

Table 1 Sizes, test configurations and determined properties of CLT panels

\begin{tabular}{|c|c|c|c|c|c|c|c|}
\hline Specimen label & $\begin{array}{l}\text { Number } \\
\text { of layers }\end{array}$ & $\begin{array}{c}\text { Thickness } \\
\text { of layer } \\
\text { [mm] }\end{array}$ & $\begin{array}{c}\text { Thickness } \\
\text { [mm] }\end{array}$ & $\begin{array}{l}\text { Width } \\
\text { [mm] }\end{array}$ & $\begin{array}{c}\text { Span in } \\
\text { bending } \\
\text { [mm] }\end{array}$ & $\begin{array}{l}\text { Loading } \\
\text { direction }\end{array}$ & $\begin{array}{c}\text { Determined } \\
\text { properties }\end{array}$ \\
\hline$B-3-20$ & 3 & 20 & 60 & 270 & 1440 & $\begin{array}{l}\text { Perpendicular } \\
\text { to plane }\end{array}$ & $\begin{array}{l}\text { Bending strength } \\
\& \text { stiffness }\end{array}$ \\
\hline$B-3-24$ & 3 & 24 & 72 & 288 & 1296 & $\begin{array}{l}\text { Perpendicular } \\
\text { to plane }\end{array}$ & $\begin{array}{l}\text { Bending strength } \\
\& \text { stiffness }\end{array}$ \\
\hline$B-3-40$ & 3 & 40 & 120 & 584 & 2880 & $\begin{array}{l}\text { Perpendicular } \\
\text { to plane }\end{array}$ & $\begin{array}{l}\text { Bending strength } \\
\text { \& stiffness }\end{array}$ \\
\hline$B-5-20$ & 5 & 20 & 100 & 576 & 2400 & $\begin{array}{l}\text { Perpendicular } \\
\text { to plane }\end{array}$ & $\begin{array}{l}\text { Bending strength } \\
\& \text { stiffness }\end{array}$ \\
\hline$S-3-20$ & 3 & 20 & 60 & 270 & 720 & $\begin{array}{l}\text { Perpendicular } \\
\text { to plane }\end{array}$ & $\begin{array}{l}\text { Shear (rolling) } \\
\text { strength \& } \\
\text { stiffness }\end{array}$ \\
\hline$S-3-24$ & 3 & 24 & 72 & 288 & 864 & $\begin{array}{l}\text { Perpendicular } \\
\text { to plane }\end{array}$ & $\begin{array}{l}\text { Shear (rolling) } \\
\text { strength \& } \\
\text { stiffness }\end{array}$ \\
\hline$S-3-40$ & 3 & 40 & 120 & 584 & 1440 & $\begin{array}{l}\text { Perpendicular } \\
\text { to plane }\end{array}$ & $\begin{array}{l}\text { Shear (rolling) } \\
\text { strength \& } \\
\text { stiffness }\end{array}$ \\
\hline$S-5-20$ & 5 & 20 & 100 & 576 & 1200 & $\begin{array}{l}\text { Perpendicular } \\
\text { to plane }\end{array}$ & $\begin{array}{l}\text { Shear (rolling) } \\
\text { strength \& } \\
\text { stiffness }\end{array}$ \\
\hline $1-3-40$ & 3 & 40 & 120 & 146 & 2628 & In plane & $\begin{array}{l}\text { Bending strength } \\
\text { \& stiffness }\end{array}$ \\
\hline $1-5-20$ & 5 & 20 & 100 & 192 & 3456 & In plane & $\begin{array}{l}\text { Bending strength } \\
\text { \& stiffness }\end{array}$ \\
\hline
\end{tabular}



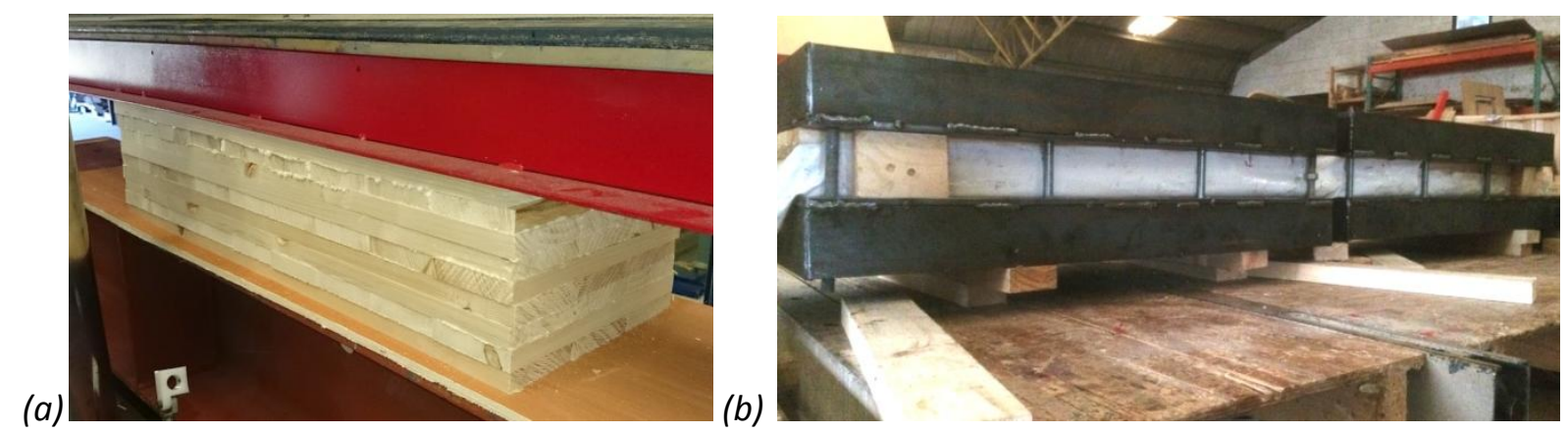

Figure 1 Manufacture of CLT panel using (a) hydraulic press, (b) bolts and steel plates

\subsection{Methodology}

The load configurations were in accordance with prEN 16351 [39]. This standard specifies a 4-point bending over a span of either 18 or 24 times the thickness $(h)$ for bending strength and stiffness determination (Figure 2), 4-point bending over a span of 12 times the thickness for shear (rolling) strength and stiffness determination perpendicular to plane (Figure 2) and 4-point bending over a span of 18 times the thickness for bending strength and stiffness in plane. When the ratio of width to thickness is equal at least 4 , bending specimens can be loaded over a span of 18 times thickness, rather than 24 [39]. However, this test setup of span of 18 times thickness was only used to test sample B-3-24. As some of these samples failed in shear and not in bending as expected, the remaining specimens were loaded over a span of 24 times the thickness. The distance between the load points was equal to six times the depth for all configurations and the panels were simply supported. Load was applied across the whole width of the CLT specimens using steel plates of a width not greater than one-half of the depth of the test specimen. The load was applied at a constant rate of displacement adjusted so that the maximum load was reached within (300 \pm 120$) \mathrm{s}$.

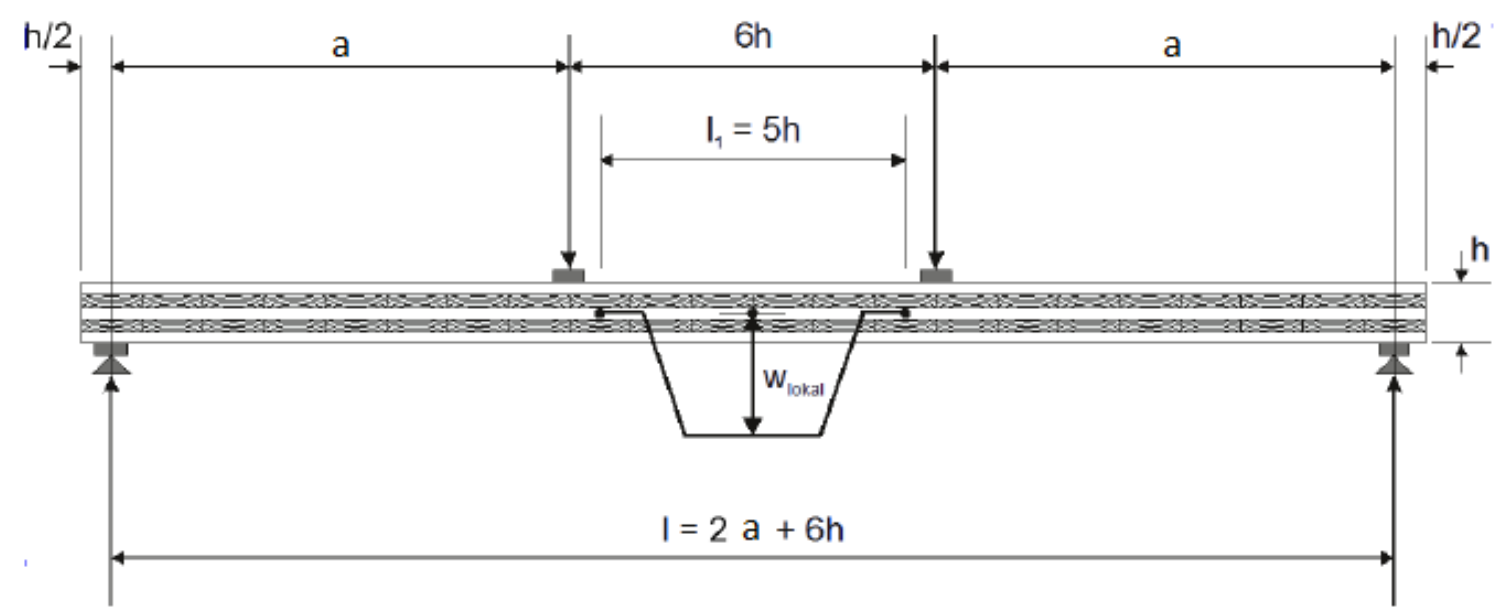

Figure 2 Test set-up for bending perpendicular to the plane ( $a=9 h)$ and rolling shear test ( $a=3 h)$ [adapted from 39] 
Testing was carried out in two stages. Initially, the specimen was loaded up to $40 \%$ of estimated maximum load, in order to determine the bending stiffness. The 'local' displacement was measured by linear variable differential transformers (LVDTs) over a central gauge length of five times the depth of the section. The 'global' displacement was measured by 2 LVDTs at mid-span on both sides of the test specimen and the mean values of measurements were used for results calculations.

In the second stage, the LVDT to measure 'local' displacement was removed in order to prevent damage. The specimen was then loaded to failure at a constant rate of displacement and the maximum load of the bending test was recorded.

The theoretical maximum bending and shear stress in specimens loaded perpendicular to the plane were calculated using the maximum test values of bending moment, and shear force, respectively. Only tests which produced the desired failure mode were taken into consideration. The following theoretical methods were applied: Layered beam theory, Gamma beam theory and Shear analogy theory. A comparison of these approximate verification procedures for CLT has been comprehensively investigated by Bogensperger et al. [26]. For the theoretical maximum shear stress (rolling) the same theoretical methods as for the bending strength were used, which are described in detail by Li [24].

For the stress calculations in this study, the value used for the modulus of elasticity parallel to the grain was $8160 \mathrm{~N} / \mathrm{mm}^{2}$, which was the mean value from the MTG acoustic measurements of boards used for CLT fabrication. Since the modulus of elasticity perpendicular to the grain is very low for timber, the contribution of the cross layers to the bending performance was excluded from the calculations. For the Gamma beam theory calculations of shear, a constant value of $50 \mathrm{~N} / \mathrm{mm}^{2}$ was used for the rolling shear modulus $G_{R}$, in accordance with Neuhaus [20]. For the stress calculation for samples loaded in-plane, it was assumed that only cross-sections with wood grains perpendicular to load are carrying the load.

The recorded 'local' and 'global' deflection measurements were plotted against the applied load to determine the stiffness of each panel. Eq. (1) and Eq. (2), based on EN 408 [41], were used to obtain the values for local and global stiffnesses, respectively.

$$
\begin{aligned}
& (E I)_{m, l}=\frac{a l_{1}\left(F_{2}-F_{1}\right)}{16\left(w_{2}-w_{1}\right)} \\
& (E I)_{m, g}=\frac{3 a l^{2}-4 a^{3}}{48\left(\frac{w_{2}-w_{1}}{F_{2}-F_{1}}-\frac{3 a}{5 G b h}\right)}
\end{aligned}
$$

In Eq. (1) and Eq. (2), $a$ is the distance between the load head and the nearest support, $I_{1}$ is equal to the gauge length ( 5 times thickness) for the local modulus measurement and $I$ is the span between the supports. $F_{1}$ and $F_{2}$ are the loads corresponding to $10 \%$ and $40 \%$ of the ultimate load $F_{\max }$, respectively and $w_{1}$ and $w_{2}$ are the deflections corresponding to these loads, respectively. $b$ is width, and $h$ is depth (thickness or high) of panel cross section. $G$ is shear modulus. 


\section{Results and analyses}

\subsection{Effect of thickness on bending performance perpendicular to the plane direction}

The detailed test results for the bending tests are shown in Table 2. These include the flexural stiffness, bending strength and failure mode for each specimen. The average and standard deviation (SD) are presented for each group. Typical flexural tension failures are shown in Figure 3 and a typical load-deflection curve is given in Figure 4 showing the brittle failure.

Table 2 Bending test results for CLT panels loaded perpendicular to the plane

\begin{tabular}{|c|c|c|c|c|c|c|c|c|c|}
\hline & \multirow{2}{*}{$\begin{array}{c}E g \times I x \\
10^{10} \\
{\left[\mathrm{Nmm}^{2}\right]}\end{array}$} & \multirow[b]{2}{*}{$\begin{array}{c}E g \\
{\left[\mathrm{~N} / \mathrm{mm}^{2}\right]}\end{array}$} & \multirow{2}{*}{$\begin{array}{c}E I \times I \times \\
10^{10} \\
{\left[\mathrm{Nmm}^{2}\right]}\end{array}$} & \multirow[b]{2}{*}{$\begin{array}{c}E l \\
{\left[\mathrm{~N} / \mathrm{mm}^{2}\right]}\end{array}$} & \multirow{2}{*}{$\begin{array}{c}\text { Max. } \\
\text { bending } \\
\text { moment } \\
{[k N m]}\end{array}$} & \multicolumn{3}{|c|}{ Max. bending stress $\left[\mathrm{N} / \mathrm{mm}^{2}\right]$} & \multirow[b]{2}{*}{$\begin{array}{l}\text { Failure } \\
\text { mode }\end{array}$} \\
\hline & & & & & & $\begin{array}{c}\text { Layered } \\
\text { beam } \\
\text { theory }\end{array}$ & $\begin{array}{c}\text { Gamma } \\
\text { beam } \\
\text { theory }\end{array}$ & $\begin{array}{c}\text { Shear } \\
\text { analogy } \\
\text { theory }\end{array}$ & \\
\hline B-3-20-1 & 3.94 & 8104 & 5.49 & 11292 & 6.4 & 40.99 & 40.08 & 41.03 & Tensile \\
\hline B-3-20-2 & 3.55 & 7304 & 5,25 & 10803 & 5.61 & 35.97 & 35.17 & 36.01 & Tensile \\
\hline B-3-20-3 & 3.57 & 7343 & 3.78 & 7772 & 5.63 & 36.05 & 35.25 & 36.09 & Tensile \\
\hline Average & 3.69 & 7,584 & 4.84 & 9,956 & 5.88 & 37.67 & 36.84 & 37.71 & \\
\hline$S D$ & 0.22 & 451.33 & 0.93 & 1906.84 & 0.44 & 2.87 & 2.81 & 2.88 & \\
\hline B-3-24-1 & 6.67 & 7,449 & 11.41 & 12,737 & 8.82 & 36.74 & 35.29 & 36.78 & Tensile \\
\hline B-3-24-2 & 6.07 & 6,779 & 6.14 & 6,853 & 5.64 & 23.53 & 22.6 & 23.55 & Delamin. \\
\hline B-3-24-3 & 7.16 & 7,995 & 10.05 & 11,225 & 11.1 & 46.27 & 44.44 & 46.33 & Tensile \\
\hline Average & 6.64 & 7,408 & 9.2 & 10,271 & 8.52 & 35.51 & 34.11 & 35.55 & \\
\hline$S D$ & 0.55 & 609.21 & 2.73 & 3055.69 & 2.74 & 11.42 & 10.97 & 11.44 & \\
\hline B-3-40-1 & 62.29 & 7,407 & 75.47 & 8,974 & 30.22 & 22.36 & 21.87 & 22.38 & Delamin. \\
\hline B-3-40-2 & 65.98 & 7,846 & 78.3 & 9,310 & 35.32 & 26.14 & 25.56 & 26.17 & Delamin. \\
\hline B-3-40-3 & 62.55 & 7,438 & 93.33 & 11,098 & 36.27 & 26.84 & 26.25 & 26.87 & Tension \\
\hline Average & 63.61 & 7,563 & 82.37 & 9,794 & 33.94 & 25.11 & 24.56 & 25.14 & \\
\hline$S D$ & 2.06 & 245.09 & 9.6 & 1141.66 & 3.26 & 2.41 & 2.36 & 2.41 & \\
\hline B-5-20-1 & 30.76 & 6,409 & 80.1 & 16,687 & 26.23 & 34.5 & 34.39 & 34.21 & Tension \\
\hline B-5-20-2 & 30.67 & 6,389 & 35.15 & 7,323 & 24.53 & 32.26 & 32.15 & 31.99 & Tension \\
\hline B-5-20-3 & 32.75 & 6,823 & 60.98 & 12,704 & 26.58 & 34.96 & 34.84 & 34.66 & Tension \\
\hline Average & 31.39 & 6,540 & 58.74 & 12,238 & 2,78 & 33.91 & 33.79 & 33.62 & \\
\hline$S D$ & 1.18 & 244.98 & 22.56 & 4699.46 & 1.1 & 1.44 & 1.44 & 1.43 & \\
\hline
\end{tabular}




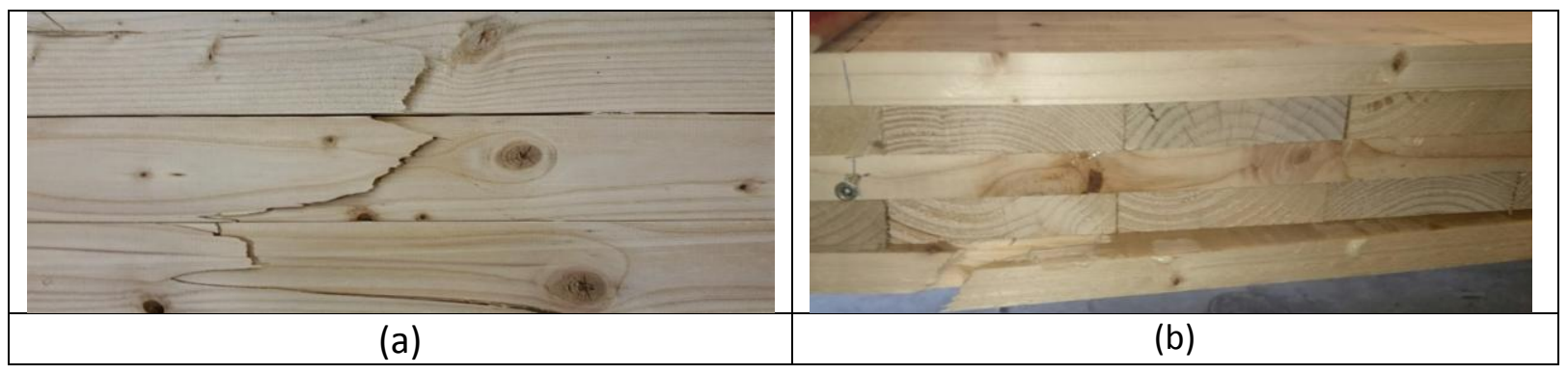

Figure 3 (a)Tensile failure on bottom of Specimen B-3-20-1; (b) Tensile failure followed by delamination of Specimen $B-5-20-1$

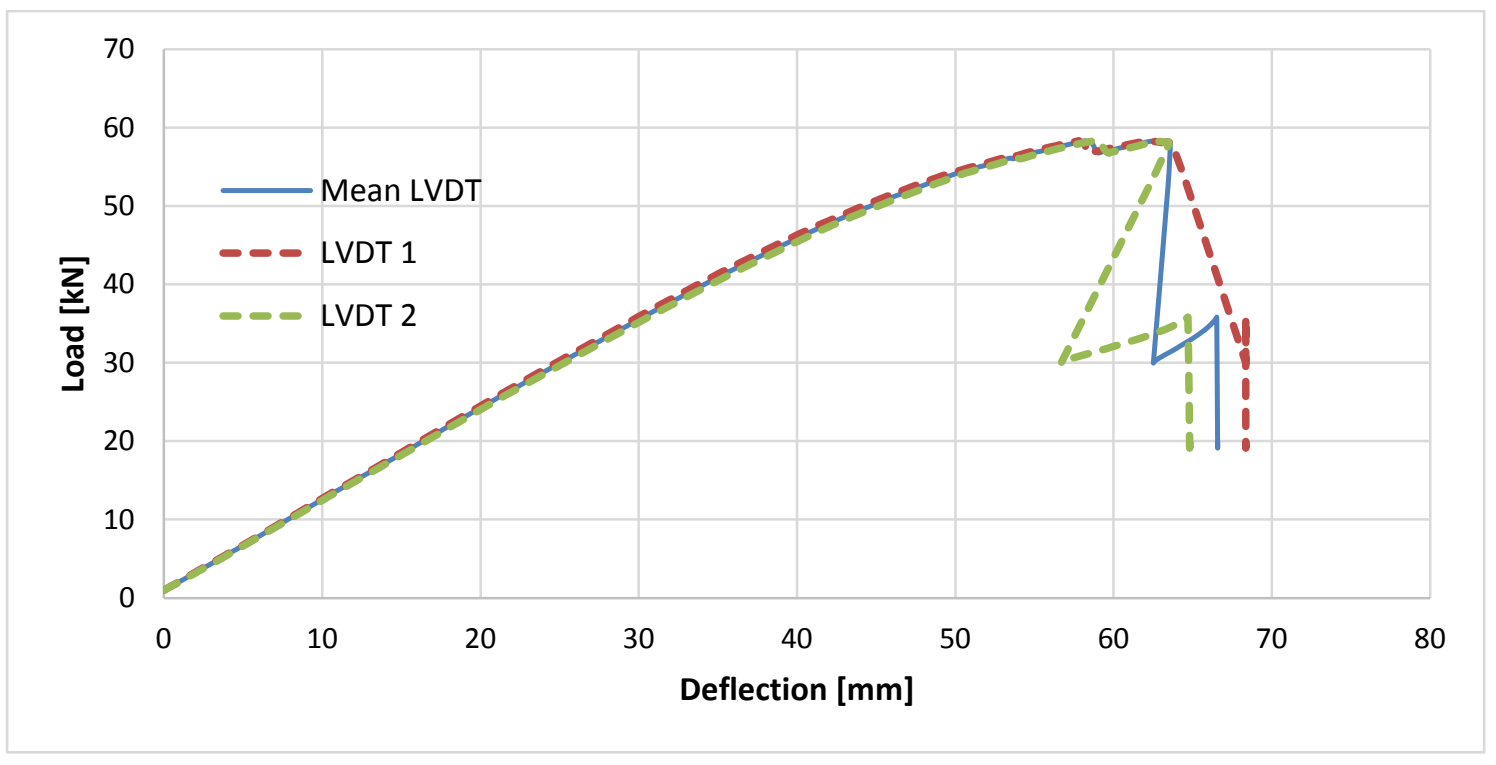

Figure 4 Load-deflection response for Specimen B-5-20-1

As seen in Table 1, the width of the tests specimens varies. In order to be able to compare stiffness results obtained from testing of specimens of different sizes, the mean flexural stiffness results for each group of specimens loaded perpendicular to the plane direction in bending were calculated per meter width. The bending properties calculated using 'global', and 'local' deformations are compared with theoretical values in Figure 5. 'Global' stiffness is calculated taking the shear modulus (G) as infinite and $500 \mathrm{~N} / \mathrm{mm}^{2}$, the value from EN 338 [42]. The highest stiffness in the investigated specimens were recorded for the thickest 3layer panels of $40 \mathrm{~mm}$ layers (B-3-40) and were 1.09E+12 $\mathrm{Nmm}^{2}$ using 'global' (for infinite G) and $1.41 \mathrm{E}+12 \mathrm{Nmm}^{2}$ using 'local' deformations, respectively. The theoretical values are calculated using Eq. (3), which based on composite theory.

$$
E I_{C L T}=E_{0} \sum_{k=1}^{n}\left(I_{k}+A_{k} y_{k}^{2}\right)
$$

where 
$E_{0}$ - mean MOE of the batch of timber boards from which the panels were manufactured

$I_{k}$ - second moment of area of lamina $\mathrm{k}$

$A_{k}$ - area of lamina $\mathrm{k}$

$y_{k}$ - distance from centroid of lamina $k$ to centroid of panel

$n$ - total number of laminae oriented parallel to the longitudinal panel direction

It was found that increasing thickness by $100 \%$ (comparing B-3-20 with B-3-40) results in a significant increase of stiffness values: by $698 \%$ and by $687 \%$ for 'global' and 'local' values, respectively. When comparing values for B-3-20 with $20 \%$ thicker B-3-24, the stiffness values were increased by $69 \%$ ('global') and $78 \%$ ('local'), but when comparing B-5-20 with $20 \%$ thicker B-3-40, values grow by $100 \%$ ('global') and $38 \%$ ('local'). It should be noted that the values calculated using 'local' deformation measurements presented greater scatter than those from 'global' deformations and should be treated with caution. This may be a consequence of local variabilities of specimens that influences 'local' deformations to the higher extent than 'global' deformation. This phenomenon was in agreement with the finding made by Ridley-Ellis et al. [43], who suggested that the main reason for the difference between the 'global' and 'local' MOE values in timber is not shear, but the variation of MOE within a specimen. Good agreement was found between the theoretical results and the values calculated from the 'global' deformations. It is seen that the influence of shear on the calculated 'global' stiffness is negligible.

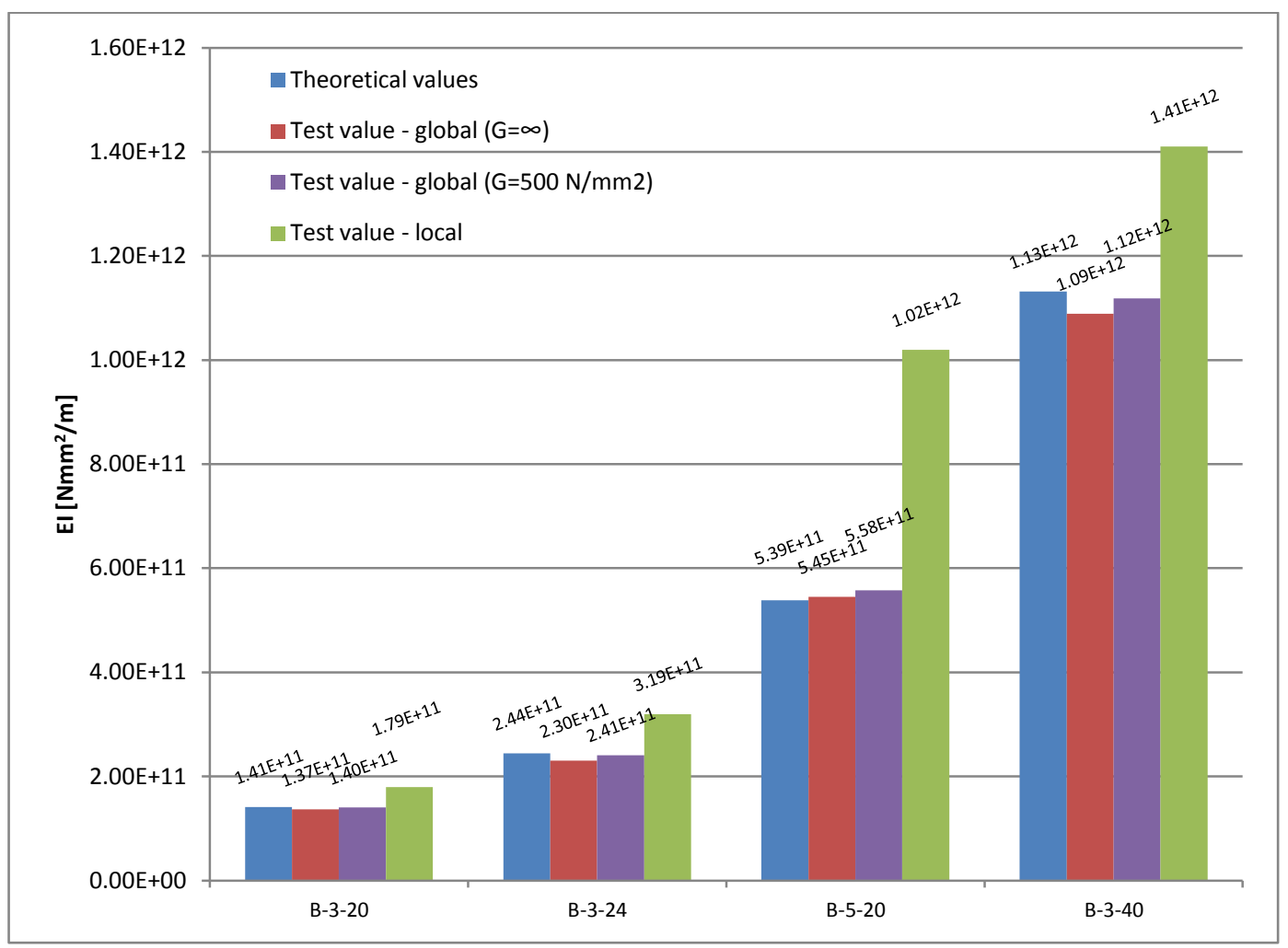

Figure 5 Mean stiffness results using 'global' and 'local' deformations in loading perpendicular to the plane direction for different CLT samples from bending tests in comparison with theoretical values 
Analyses of the data for samples of different thicknesses for 3 layer panels revealed a good correlation between the changes in the mean stiffness and thickness values, which is presented in Figure 6 . The ratios representing (i) the theoretical values, (ii) the experimental values calculated using the determined MOE parallel to the wood grain direction, the second moment of area of longitudinal layers, the 'global' values and an infinite shear modulus ( $G=\infty$ ), (iii) the experimental values calculated using the 'global' values and a shear modulus of $\mathrm{G}=500 \mathrm{~N} / \mathrm{mm}^{2}$, and (iv) the experimental values calculated using the 'local' values are plotted. The values for the 'local' and 'global' (infinite G) MOE were very close to the theoretical values, and might be used as indicators of the effect of thickness on bending performance. On the basis of these results, which match closely with the theoretical values, it is likely that the stiffness results from bending tests can be used to accurately predict stiffness values for panels of different thicknesses.

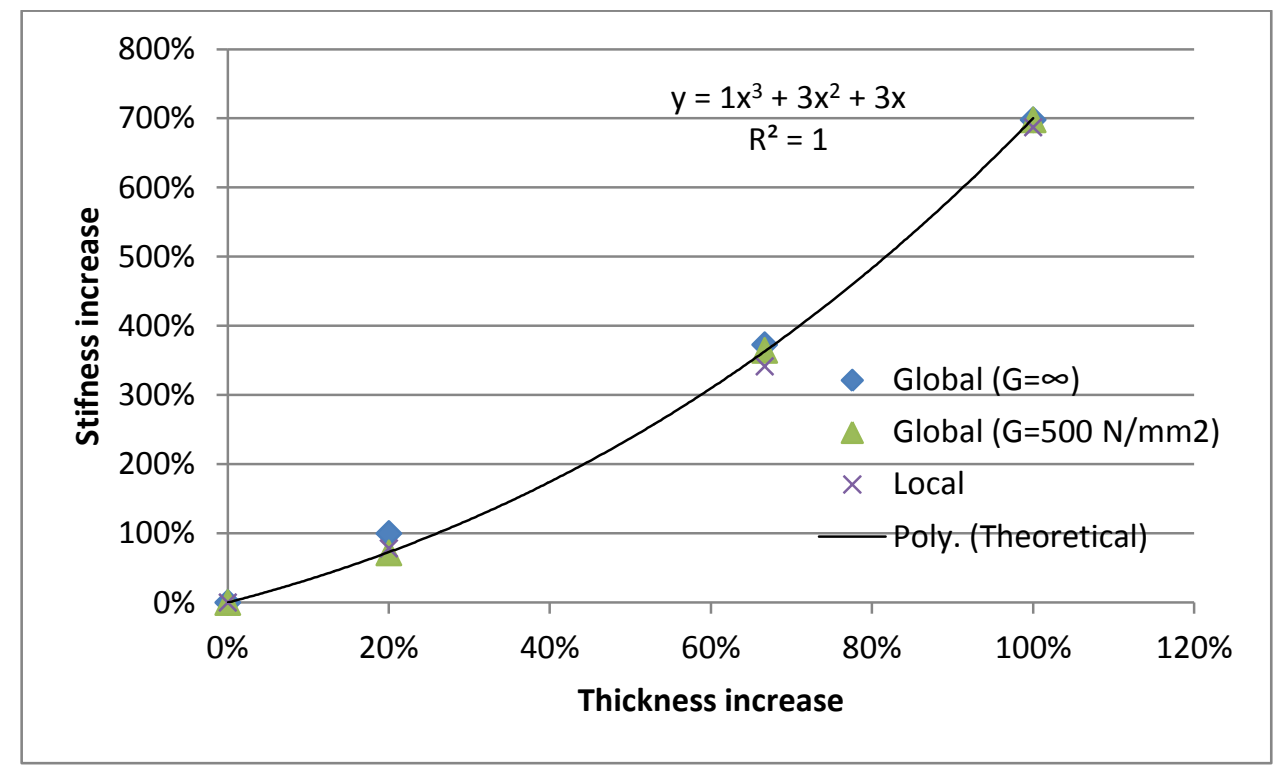

Figure 6 Correlation between CLT panel thickness increase and stiffness increase for bending (B) samples

Figure 7 presents the mean bending strength results for specimens loaded in bending perpendicular to the plane direction for different CLT groups. For some of the specimens, minor manufacturing defects resulted in delamination failure rather than bending or shear failure, therefore, these results were excluded from calculations. This also emphasises the importance of proper quality production, especially the bonding process. Only the results for which bending failure initially at the tension face was recorded, as expected, were taken into consideration. The highest values of approximately $37 \mathrm{~N} / \mathrm{mm}^{2}$ were obtained for the thinnest samples (B-3-20), and the lowest of approximately $27 \mathrm{~N} / \mathrm{mm}^{2}$ for the thickest (B-340). Such values are high for timber of C16 strength grade, confirming excellent performance of CLT from this timber. Based on these results, there is a general trend that the thicker the CLT panel is the lower its bending strength. It should be noted that values for groups B-3-24 and B-3-40 are from one specimen only, and should be treated with caution, however the standard deviations for B-3-20 and B-5-20 are relatively low, and equal to 2.8 
$\mathrm{N} / \mathrm{mm}^{2}$, and $1.4 \mathrm{~N} / \mathrm{mm}^{2}$, respectively. These strength results are slightly higher than results obtained for CLT made of Scottish Sitka spruce, by Crawford et al. [37], which varied between $18 \mathrm{~N} / \mathrm{mm}^{2}$ and $35 \mathrm{~N} / \mathrm{mm}^{2}$. The highest value in this study was found for the thinner panels. For panels that were face- and edge-bonded, the mean bending strengths for 100 $\mathrm{mm}$ thick panels was $35 \mathrm{~N} / \mathrm{mm}^{2}$ compared to $28 \mathrm{~N} / \mathrm{mm}^{2}$ for $120 \mathrm{~mm}$ thick panels. Threelayer $120 \mathrm{~mm}$ thick face-bonded panels, similar to those in the present study, had a mean bending strength of $18 \mathrm{~N} / \mathrm{mm}^{2}$ compared to $26 \mathrm{~N} / \mathrm{mm}^{2}$ found here. Nevertheless, further tests are required to confirm the observed tendency of strength decease with increased thickness.

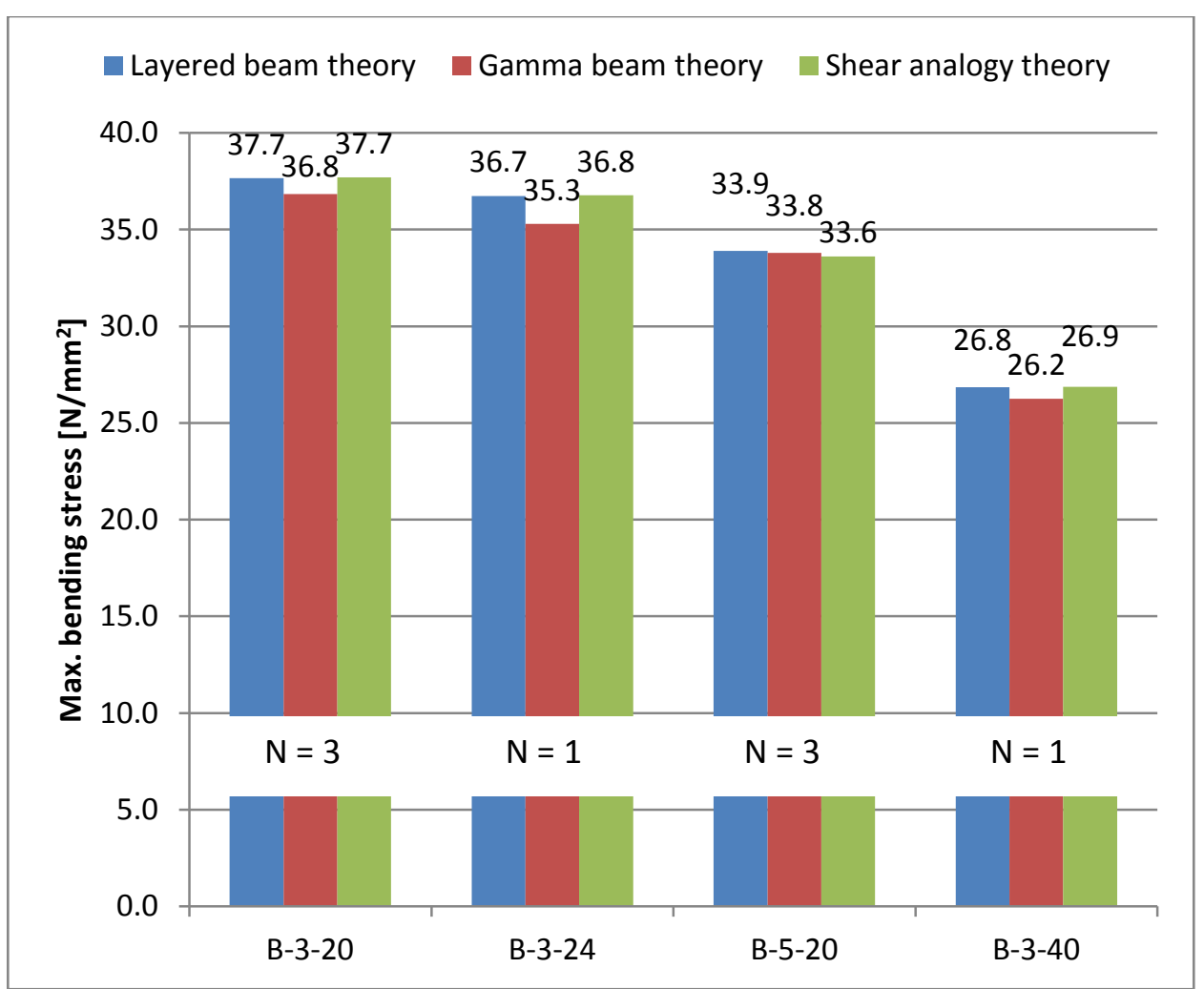

Figure 7 Mean bending strength results in loading perpendicular to the plane direction for different CLT samples ( $N$ indicates number of specimens with bending failure mode)

The values of the bending strength calculated using Layered beam theory and the Shear analogy theory were almost identical ( $<0.5 \%$ difference) for all specimens. The values for $3-$ layer panels using the Gamma beam theory were lower by $2 \%-4 \%$, which might be associated with the usage of a conservative value of $50 \mathrm{~N} / \mathrm{mm}^{2}$ for the rolling shear modulus $\mathrm{G}_{\mathrm{R}}$.

\subsection{Effect of thickness on shear performance perpendicular to the plane direction}

The detailed test results for the shear tests are shown in Table 3. A typical rolling shear failure is shown in Figure 8 and the non-linear load-deflection response typical of the shear tests is shown in Figure 9. 
Table 3 Shear test results

\begin{tabular}{|c|c|c|c|c|c|c|c|c|c|}
\hline & \multirow{2}{*}{$\begin{array}{l}E g x I x \\
10^{10} \\
{\left[\mathrm{Nmm}^{2}\right]}\end{array}$} & \multirow{2}{*}{$\begin{array}{l}\mathrm{Eg} \\
{\left[\mathrm{N} / \mathrm{mm}^{2}\right]}\end{array}$} & \multirow{2}{*}{$\begin{array}{l}E l x I x \\
10^{10} \\
{\left[\mathrm{Nmm}^{2}\right]}\end{array}$} & \multirow{2}{*}{$\begin{array}{l}E l \\
{\left[N / \mathrm{mm}^{2}\right]}\end{array}$} & \multirow{2}{*}{$\begin{array}{l}\text { Max. } \\
\text { shear } \\
\text { force } \\
{[k N]}\end{array}$} & \multicolumn{3}{|c|}{ Max. shear stress $\left[\mathrm{N} / \mathrm{mm}^{2}\right]$} & \multirow{2}{*}{$\begin{array}{l}\text { Failure } \\
\text { mode }\end{array}$} \\
\hline & & & & & & $\begin{array}{l}\text { Layered } \\
\text { beam } \\
\text { theory }\end{array}$ & $\begin{array}{l}\text { Gamma } \\
\text { beam } \\
\text { theory }\end{array}$ & $\begin{array}{l}\text { Shear } \\
\text { analogy } \\
\text { theory }\end{array}$ & \\
\hline S-3-20-1 & 2.62 & 5383 & 3.59 & 7384 & 22.17 & 1.9 & 1.75 & 1.9 & Shear \\
\hline S-3-20-2 & 3.08 & 6345 & 4.22 & 8687 & 23.73 & 2.03 & 1.87 & 2.03 & Shear \\
\hline S-3-20-3 & 3.07 & 6322 & 4.63 & 9526 & 26.87 & 2.3 & 2.12 & 2.3 & Shear \\
\hline Average & 2.92 & 6,017 & 4.15 & 8,533 & 24.25 & 2.08 & 1.91 & 2.07 & \\
\hline$S D$ & 0.27 & 548.52 & 0.52 & 1079.28 & 2.39 & 0.21 & 0.19 & 0.2 & \\
\hline S-3-24-1 & 4.89 & 5,461 & 5.89 & 6,575 & 27.46 & 1.84 & 1.69 & 1.84 & Shear \\
\hline S-3-24-2 & 4.93 & 5,499 & & & 24.86 & 1.67 & 1.53 & 1.66 & Shear \\
\hline S-3-24-3 & 4.7 & 5,252 & 6.11 & 6,826 & 24.38 & 1.63 & 1.5 & 1.63 & Shear \\
\hline Average & 4.84 & 5,404 & 6 & 6,700 & 25.57 & 1.71 & 1.57 & 1.71 & \\
\hline$S D$ & 0.12 & 133.11 & 0.16 & 177.93 & 1.66 & 0.11 & 0.1 & 0.11 & \\
\hline S-3-40-1 & 39.49 & 4,696 & 92.9 & 11,047 & 48.39 & 0.96 & 0.88 & 0.96 & Shear \\
\hline S-3-40-2 & 45.03 & 5,355 & 55.76 & 6,631 & 58.75 & 1.16 & 1.07 & 1.16 & Shear \\
\hline S-3-40-3 & 33.8 & 4,019 & 39.89 & 4,743 & 58.16 & 1.15 & 1.06 & 1.15 & Shear \\
\hline Average & 39.44 & 4,690 & 62.85 & 7,474 & 55.1 & 1.09 & 1 & 1.09 & \\
\hline$S D$ & 5.62 & 668.1 & 27.21 & 3235.69 & 5.82 & 0.12 & 0.11 & 0.12 & \\
\hline S-5-20-1 & 20.24 & 4,217 & 22.94 & 4,780 & 31.01 & 0.65 & 0.66 & 0.65 & Delamin. \\
\hline S-5-20-2 & 23.18 & 4,829 & 31.14 & 6,488 & 63.4 & 1.33 & 1.35 & 1.33 & Shear \\
\hline S-5-20-3 & 22.34 & 4,653 & 27.82 & 5,797 & 52.78 & 1.11 & 1.12 & 1.1 & Shear \\
\hline Average & 21.92 & 4,567 & 27.3 & 5,688 & 49.06 & 1.03 & 1.04 & 1.03 & \\
\hline$S D$ & 1.51 & 314.97 & 4.12 & 859.23 & 16.51 & 0.35 & 0.35 & 0.35 & \\
\hline
\end{tabular}

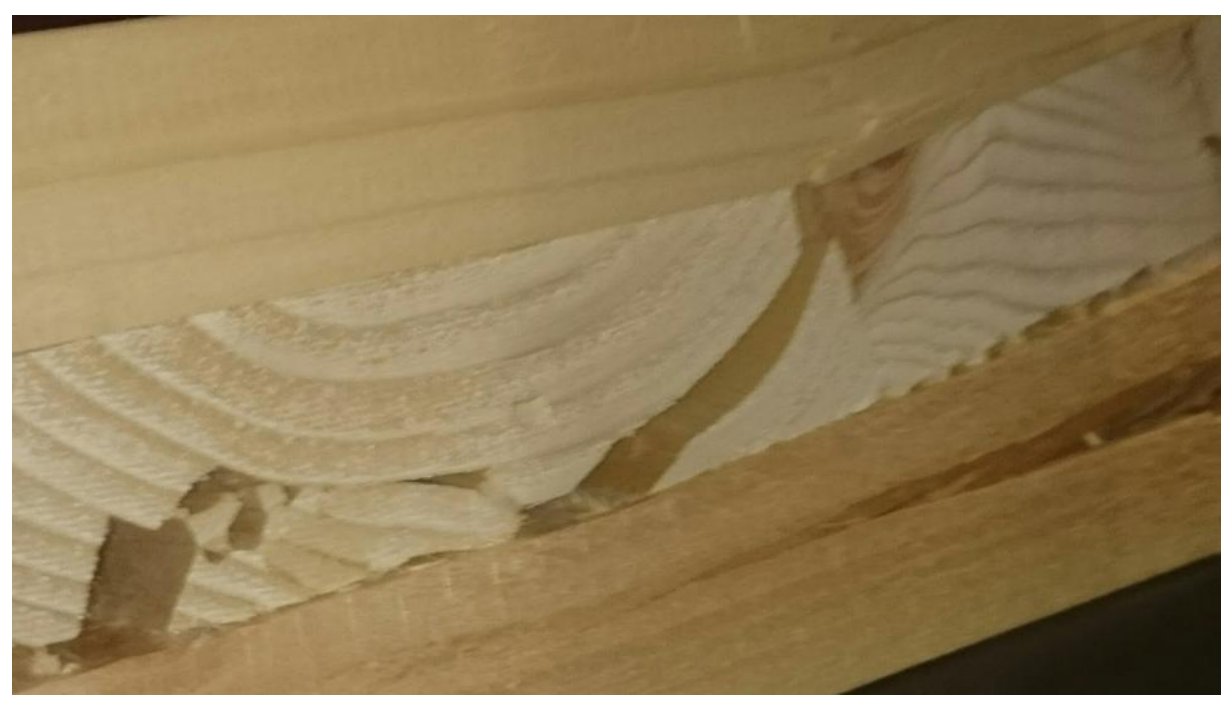

Figure 8 Rolling shear failure in Specimen S-3-40-2 


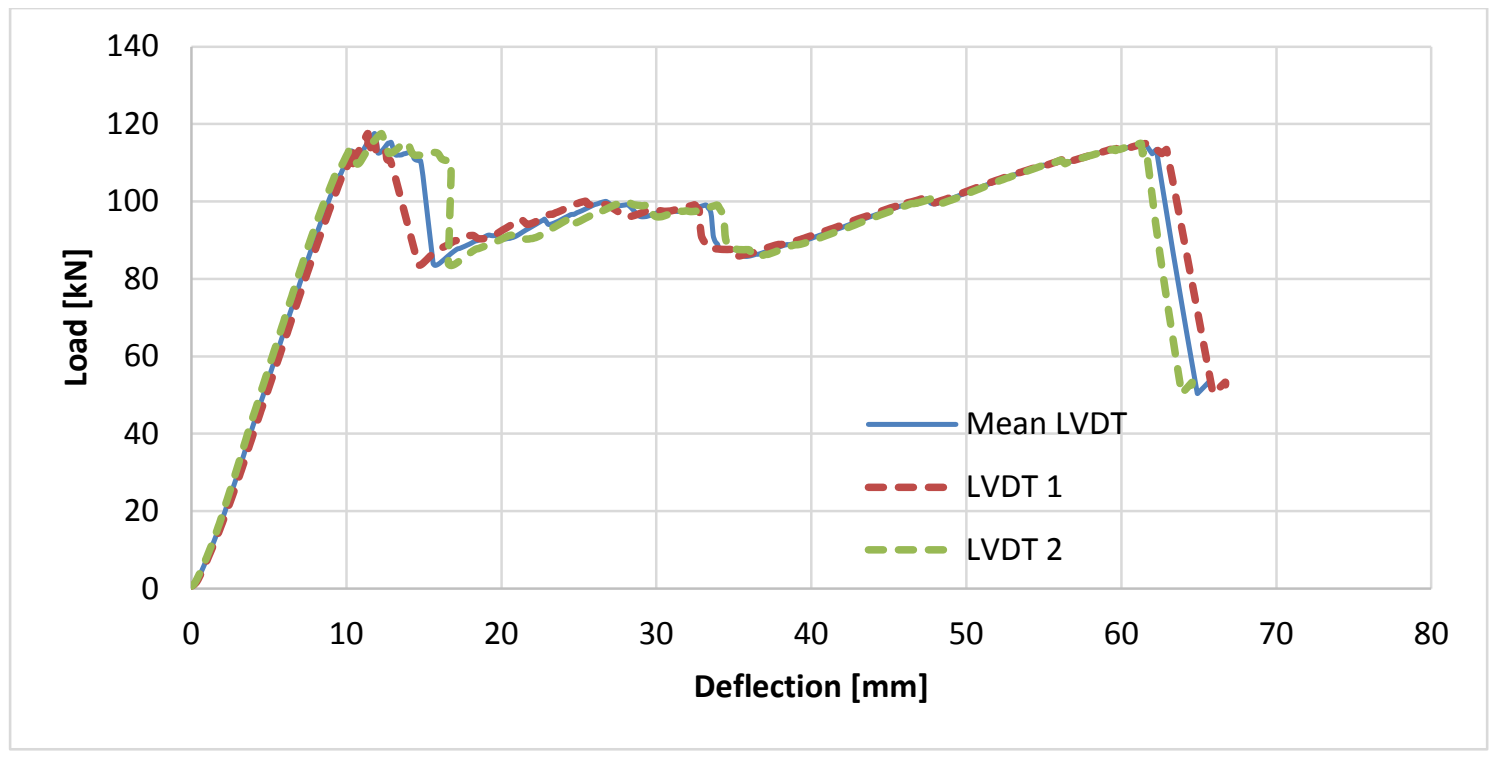

Figure 9 Load-deflection response for Specimen S-3-40-2

As the specimen width varies for each series, the mean flexural stiffness values per unit width for different CLT samples calculated from the shear test measurements are shown in Figure 10. In spite of the general trend of increasing flexural stiffness with increasing panel thickness, the values are lower than those found in the bending tests. The highest stiffnesses in the investigated samples were recorded for the thickest 3-layer panels of 40 mm layers (S-3-40) and were $6.75 \mathrm{E}+11 \mathrm{Nmm}^{2}$ using 'global' and $1.08 \mathrm{E}+12 \mathrm{Nmm}^{2}$ using 'local' deformations, respectively. It was observed that increasing thickness results in an increase in stiffness values comparing S-3-20 with S-3-40 by $524 \%$ and by $601 \%$ for 'global' (infinite G) and 'local' values. When comparing the values for S-3-20 with $20 \%$ thicker S-3-24, the stiffness values were increased by 55\% ('global') and 36\% ('local'), but when comparing S-520 with $20 \%$ thicker S-3-40, the values grow by $77 \%$ ('global') and $127 \%$ ('local'). In general, for the shorter samples (S), the flexural stiffness calculated using the 'global' deformation is significantly different to the theoretical value even when the shear deformation is taken into account. The flexural stiffness should be determined using bending tests. 


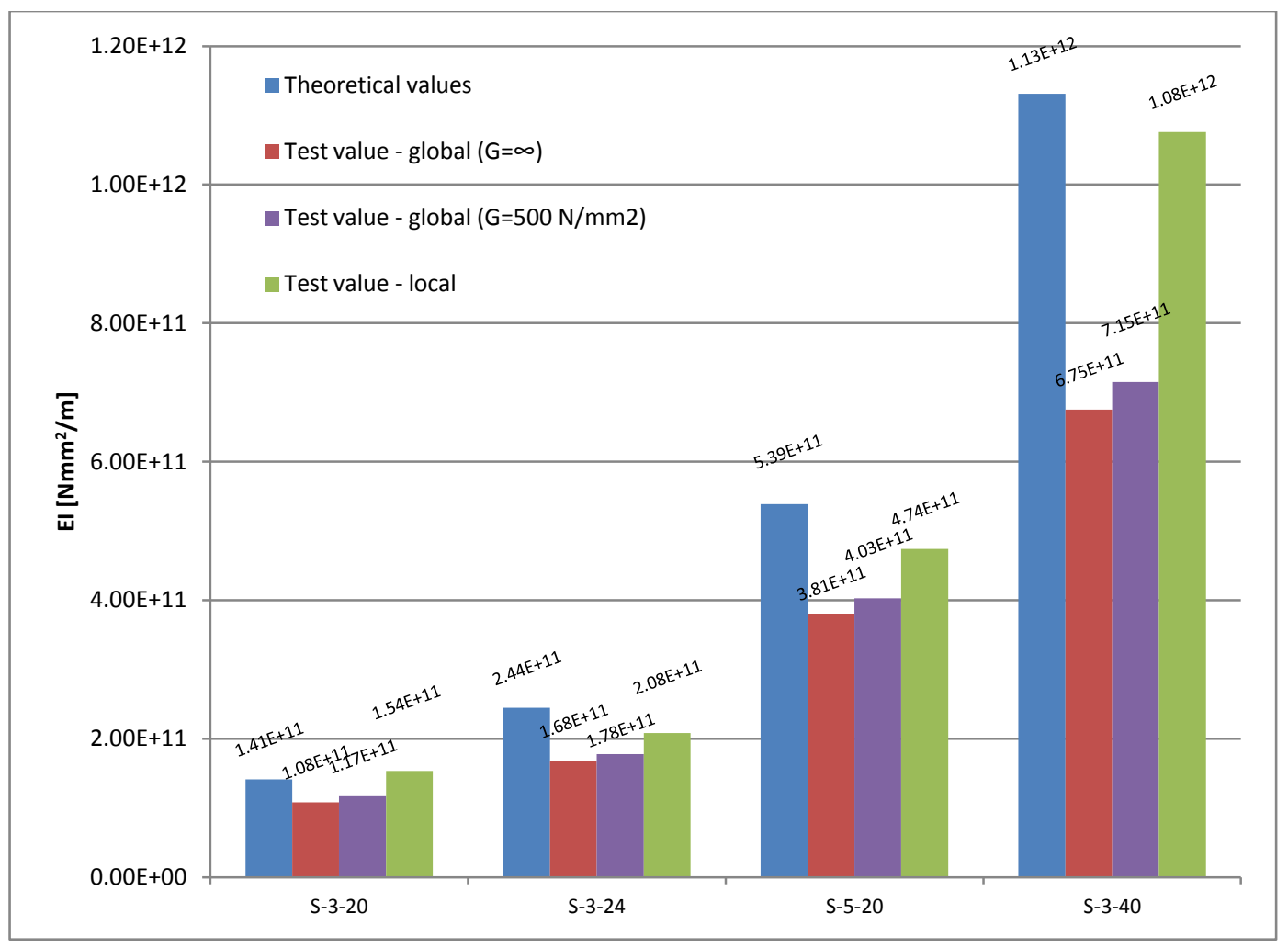

Figure 10 Mean stiffness results using 'global' and 'local' in loading perpendicular to the plane direction for different CLT samples for shear properties determination in comparison with theoretical value

A similar analysis, as for the specimens with longer span (B), was carried out for the data obtained from the tests on the shorter 3-layer samples (S) of different thicknesses. The correlation between the theoretical and test values is less strong than for the bending samples (B), which is presented in Figure 11. However, for this case 'local' values seemed to be better stiffness indicator, since shear deformation is underestimating 'global' stiffness. 


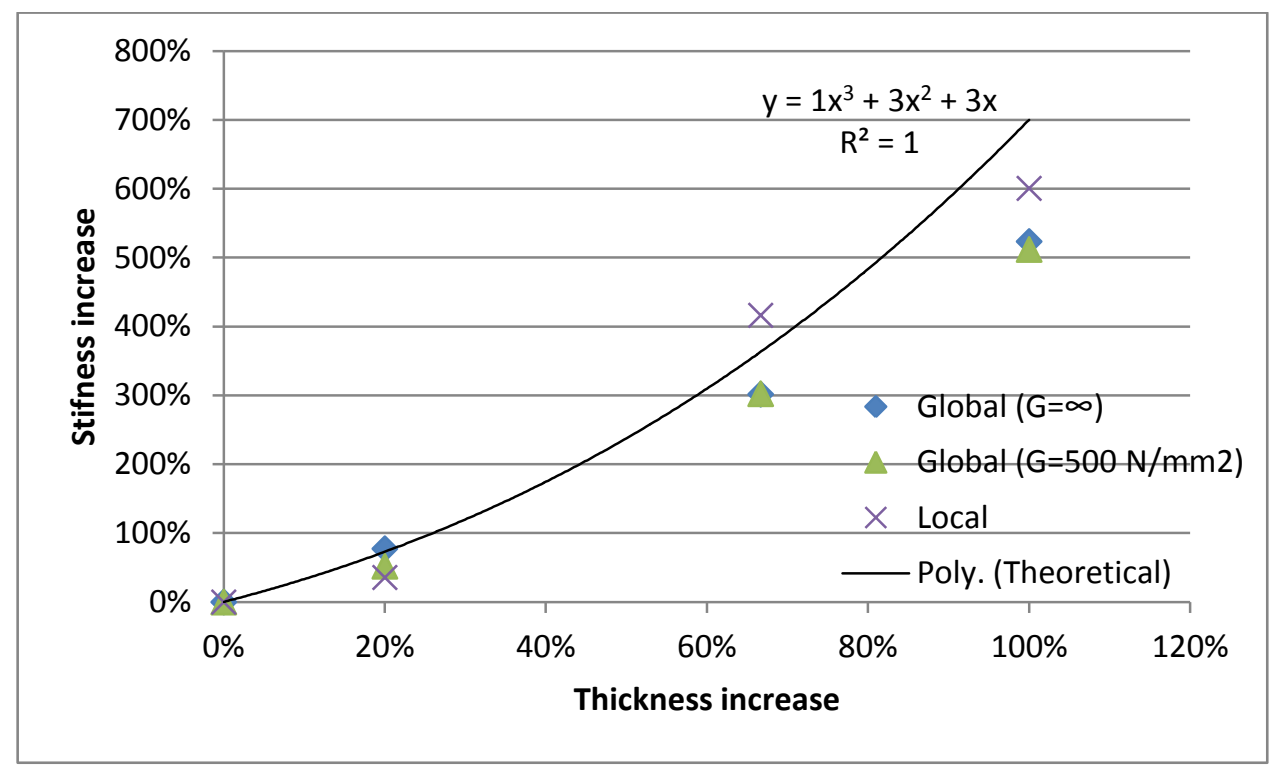

Figure 11 Correlation between CLT panel thickness increase and stiffness increase for shear(S) samples

Figure 12 presents the mean shear strength for different CLT samples when loaded perpendicular to the plane direction. Only the results for which shear failure was recorded, as expected, were taken into consideration. The results for specimens: S-3-20, S-3-24, S-520 , and S-3-40 were approximately $2.0 \mathrm{~N} / \mathrm{mm}^{2}, 1.7 \mathrm{~N} / \mathrm{mm}^{2}, 1.2 \mathrm{~N} / \mathrm{mm}^{2}$, and $1.0 \mathrm{~N} / \mathrm{mm}^{2}$, respectively. Standard deviations for all 3-layer CLT groups were $0.1 \mathrm{~N} / \mathrm{mm}^{2}$, and $0.3 \mathrm{~N} / \mathrm{mm}^{2}$ for 5-layer group. A similar trend, as for bending strength, was observed; the thicker the CLT panel is the lower shear strength. 


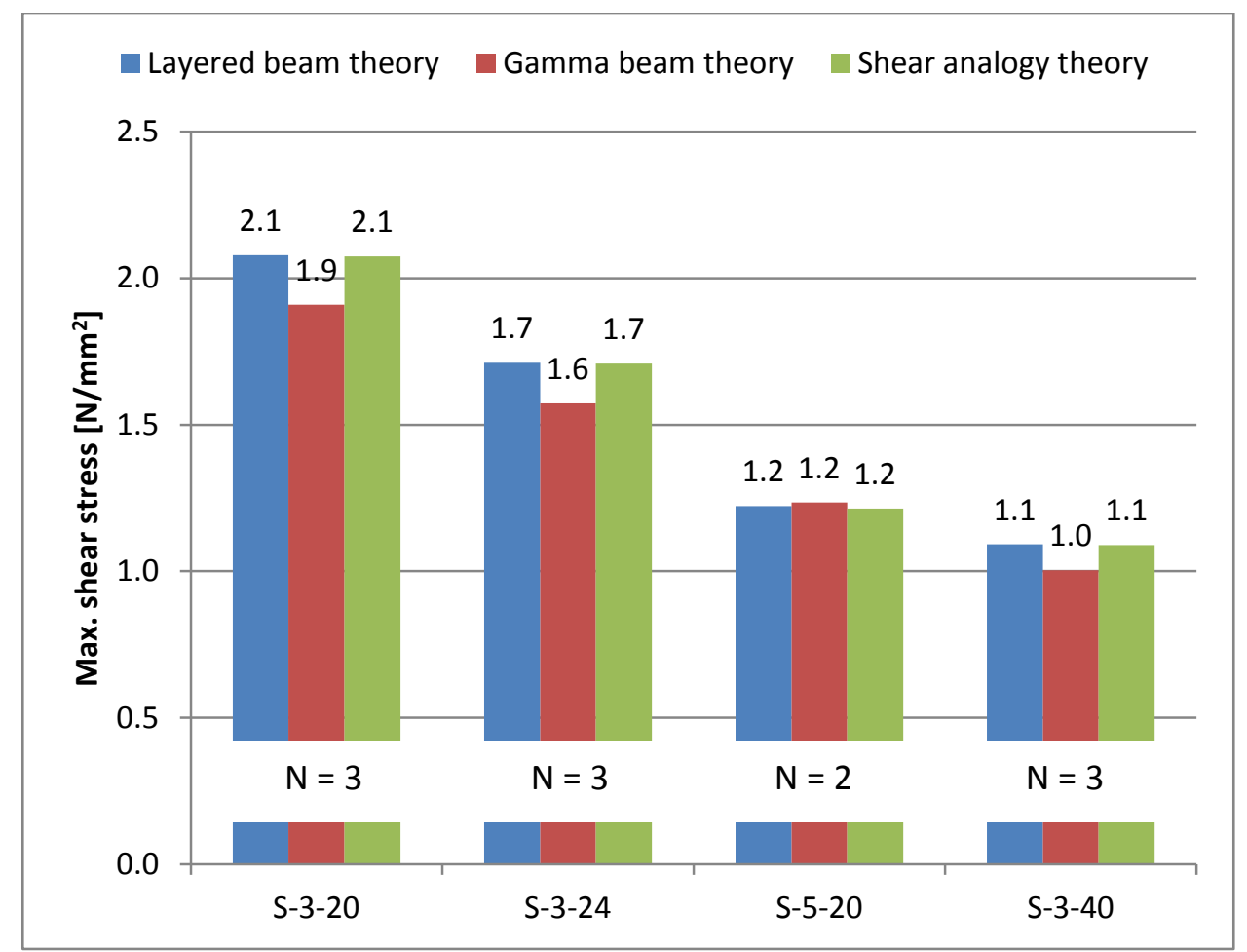

Figure 12 Mean shear strength results in loading perpendicular to the plane direction for different $C L T$ samples ( $N$ indicates number of specimens with shear failure mode)

The established mean values are in agreement with the study by Blass and Görlacher [20], where rolling shear results ranged from $1.2 \mathrm{~N} / \mathrm{mm}^{2}$ to $2.1 \mathrm{~N} / \mathrm{mm}^{2}$, and a characteristic value of $1.0 \mathrm{~N} / \mathrm{mm}^{2}$ for the rolling shear strength of European spruce was proposed. Furthermore, the results from this study are close to those established in the thesis by Li [23], where the mean rolling shear strength values ranged from $1.4 \mathrm{~N} / \mathrm{mm}^{2}$ to $1.8 \mathrm{~N} / \mathrm{mm}^{2}$, and were lower for larger specimens.

\subsection{Effect of size on the in-plane bending performance}

The values of the mean in-plane flexural stiffness (for all 3 specimens) when loaded in the in-plane direction for two different CLT types are presented in Figure 13. 'Global' and 'local' deformations are compared with theoretical values. In order to be able to compare the stiffness results obtained from testing for specimens of different heights, values were calculated per $100 \mathrm{~mm}$ height. 


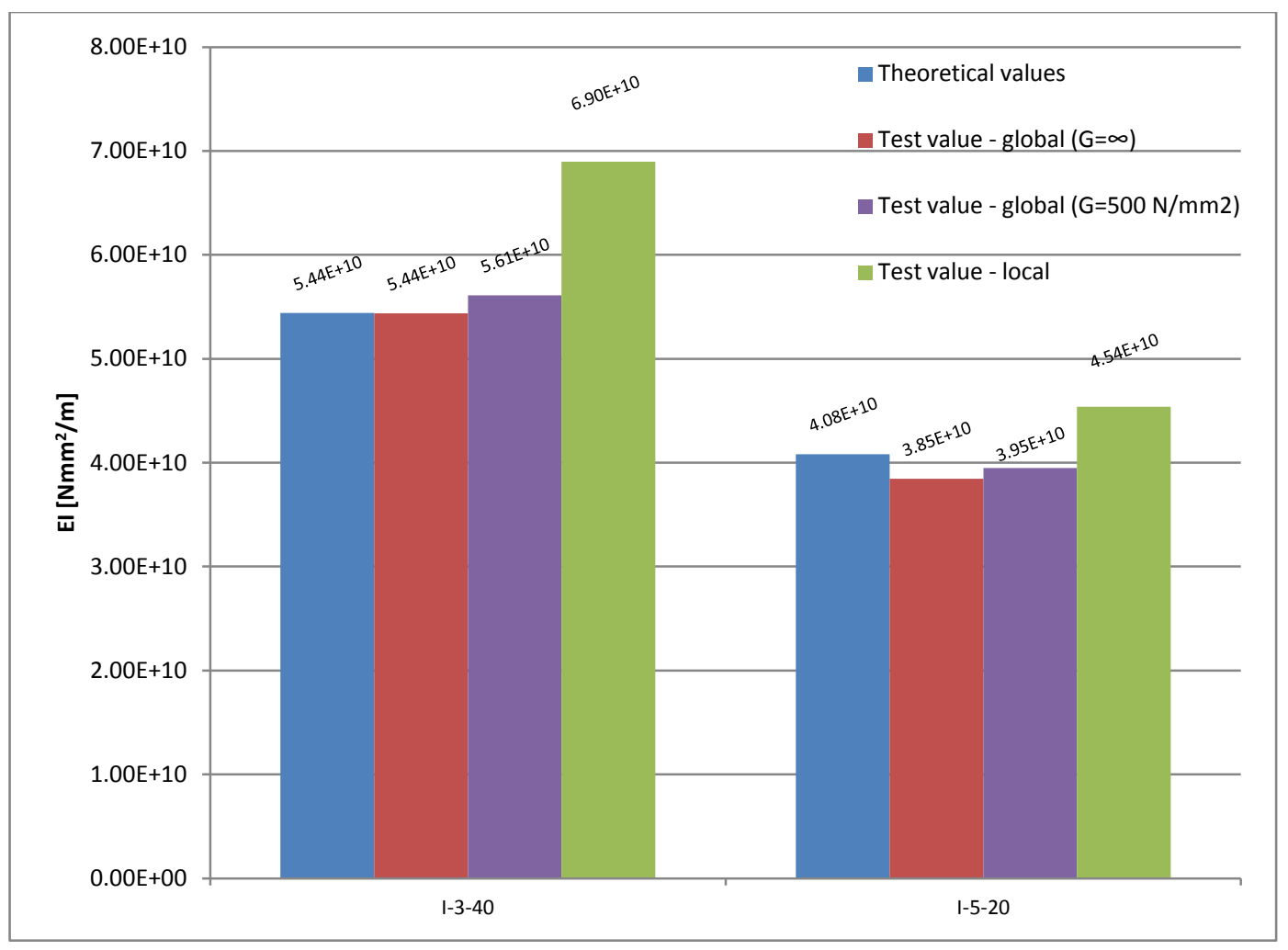

Figure 13 Mean stiffness results using 'global' deformation in the plane direction loading for different CLT samples for bending properties determination

As expected, higher values of stiffness were obtained for thicker 1-3-40 panels. For specimens loaded in the plane direction, the stiffness test results obtained using 'global' deflection, unlike 'local', were clearly in line with the theoretical values. The highest standard deviation of $1.13 \mathrm{E}+10 \mathrm{~N} / \mathrm{mm}^{2}$ was obtained for 'local' stiffness of group I-3-40. Furthermore, the mean in-plane bending strength and standard deviation results for types, I-3-40 and I-5-20, were $16.2 \mathrm{~N} / \mathrm{mm}^{2}$ and $16.3 \mathrm{~N} / \mathrm{mm}^{2}$, respectively, with the corresponding standard deviations of $3.3 \mathrm{~N} / \mathrm{mm}^{2}$ and $1.6 \mathrm{~N} / \mathrm{mm}^{2}$. The results for both groups were very similar and were approximately $16 \mathrm{~N} / \mathrm{mm}^{2}$, which is the characteristic bending strength for C16 timber, in accordance with EN-338 [42]. Therefore, results give an indication that for such configuration of Sitka spruce there is no the additional strengthening effect by laminating timber cross-wise for in-plane bending behaviour.

\section{Conclusions}

Based on the investigations presented on the mechanical performance of CLT made from Irish-grown Sitka spruce, the following conclusions can be formulated:

- The highest maximum bending stress values were obtained for the thinnest samples (B-3-20), and the lowest for the thickest (B-3-40). Based on these results, there is a general tendency that the thicker the CLT panel the lower bending strength. However, further tests are required to confirm this trend. 
- Rolling shear strength is also adversely influenced by increasing CLT thickness. Mean values for CLT, made from Sitka spruce, of different thicknesses ranged from 1.0 $\mathrm{N} / \mathrm{mm}^{2}$ to $2.0 \mathrm{~N} / \mathrm{mm}^{2}$.

- The highest stiffnesses in the investigated samples were recorded for the thickest 3layer panels of $40 \mathrm{~mm}$ layers and the lowest values were obtained for the thinnest 3 layer panels of $20 \mathrm{~mm}$ layers. It was found that the stiffnesses from bending specimens, calculated using the 'global' deformations, closely match the results for the theoretical stiffness results. On the other hand, the 'global' MOE is inadequate indicator of MOE for shorter panels.

- No additional strengthening effect was observed by laminating timber cross-wise for in-plane bending behaviour.

- The importance of proper quality control, especially for the bonding process should not be overlooked. Manufacturing defects can result in delamination failure rather than bending or shear failure.

\section{Acknowledgments}

This work has been carried out as part of the project entitled 'Innovation in Irish timber Usage' (project ref. 11/C/207) funded by the Department of Agriculture, Food and the Marine of the Republic of Ireland under the FIRM/RSF/COFORD scheme.

\section{References}

[1] Brandner R. Stochastic System Actions and Effects in Engineered Timber Products and Structures. PhD Thesis, Institute of Timber Engineering and Wood Technology, Graz University of Technology, 2012, p. 467.

[2] Brandner R. Production and Technology of Cross Laminated Timber (CLT): A state-of-the-art Report. ECOST-MEETING-FP1004-210513-028873, ISBN 185790181 9, 2013, p. 3-36.

[3] Jöbstl RA, Bogensperger T, Schickhofer G. In-plane shear strength of Cross Laminated Timber. CIB-W18, St. Andrews, Canada, 2008, p. 41-21-3.

[4] Mestek P, Kreuzinger H, Winter S. Design of cross laminated timber (CLT). WCTE 2008 - 10th World Conference on Timber Engineering, Miyazaki, Japan, 2008.

[5] Vessby J, Enquist B, Petersson H, Alsmarker T. Experimental study of cross-laminated timber wall panels. European Journal of Wood Products, 67, 2009, p. 211-218.

[6] Fortune AL, Quenneville P. Feasibility study of New Zealand radiata pine crosslam, in Setunge $S$ (Eds.). Incorporating sustainable practise in mechanics and structures of materials, CRC Press, 2010.

[7] Leonardo da Vinci Pilot Project. Handbook 1. Timber structures, Educational Materials for Designing and Testing Timber Structures - TEMTIS, 2008.

[8] Crespell P, Gagnon S. Cross Laminated Timber: a Premier. FPInnovations, 2010.

[9] Yeh B, Gagnon S, Williamson T, Pirvu C, Lum C, Kretschmann D. The North American product standard for cross-laminated timber. Wood Design Focus, 22(2), 2009, p. 13-21.

[10] Hindman DP, Bouldin JC. Mechanical properties of southern pine cross-laminated timber. Journal of Materials in Civil Engineering 27 (9), 2015, p. 1-7. 
[11] ANSI/APA PRG 320-2012. Standard for Performance-Rated Cross-Laminated Timber. APA - The Engineered Wood Association, Tacoma, 2012.

[12] Okabe M, Yasumura M, Kobayashi K, Fujita K. Prediction of bending stiffness and moment carrying capacity of sugi cross-laminated timber. Journal of Wood Science, 60, 2014 p.49-58.

[13] Park H-M, Fushitani M, Sato K, Kubo T, Byeon H-S. Bending creep performances of three-ply cross-laminated woods made with five species. Journal of Wood Science, 52(3), 2006, pp.220229.

[14] Ido H, Nagao H, Harada M, Kato H, Ogiso J, Miyatake A. Effects of the width and lay-up of sugi cross-laminated timber (CLT) on its dynamic and static elastic moduli, and tensile strength. Journal of Wood Science.62(1),, 2016, 101-108.

[15] Wang Z, Gong M, Chui Y-H. Mechanical properties of laminated strand lumber and hybrid crosslaminated timber. Construction and Building Materials, 101, 2015, p.622-627.

[16] Niederwestberg J, Chui YH. Characterizing influence of laminate characteristics on elastic properties of single- layer in cross laminated timber, Proceedings of World Conference on Timber Engineering, Quebec City, Canada, 2014, p.5-6.

[17] Blass HJ, Fellmoser P. Design of solid wood panels with cross layers. Proceedings of 8th World Conference on Timber Engineering, 2014, p. 1001-1006.

[18] Steiger R, Gülzow A. Validity of bending tests on strip-shaped specimens to derive bending strength and stiffness properties of cross-laminated solid timber (X-lam). Proceedings of 'The Future of Quality Control for Wood \& Wood Products', The Final Conference of COST Action E53, 2010, p.4-7.

[19] Steiger R, Gülzow A, Czaderski C, Howald MT, Niemz P. Comparison of bending stiffness of cross-laminated solid timber derived by modal analysis of full panels and by bending tests of strip-shaped specimens. European Journal of Wood and Wood Products, 70, 2012,p.141-153.

[20] Blass HJ, Görlacher R. Rolling shear in structural bonded timber elements. Proceedings of International Conference on Wood and Wood Fiber Composites, 2000, p.327-337.

[21] Neuhaus FH. Elastizitätszahlen von Fichten- holz in Abhängigkeit von der Holzfeuchtigkeit. Mitteilung, Report Nr. 81-8. Institut für Konstruktiven Ingenieurbau. Ruhr-Universität Bochum, 1981.

[22] Zhou QY, Gong M, Chui Y-H, Mohammad M. Measurement of rolling shear modulus of cross laminated timber: Exploratory study using downscaled specimens under variable span bending tests. Proceedings of International Conference on Biobase Material Science and Engineering, BMSE, 2012, p.36-40.

[23] Zhou QY, Gong M, Chui Y-H, Mohammad M. Measurement of rolling shear modulus and strength of cross-laminated timber using bending and two-plate shear tests. Wood and Fiber Science, 46(2), 2014, p.1-11.

[24] Li Y. Duration-of-load and size effects on the rolling shear strength of cross laminated timber. PhD thesis, The Faculty Of Graduate And Postdoctoral Studies (Forestry), The University Of British Columbia, 2015.

[25] Saavedra Flores El, Saavedra K, Hinojosa J, Chandra Y, Das R. Multi-scale modelling of rolling shear failure in cross-laminated timber structures by homogenisation and cohesive zone models. International Journal of Solids and Structures. DOI:10.1016/j.ijsolstr.2015.11.027, 2015.

[26] Bogensperger T, Silly G, Schickhofer G. Comparison of Methods of Approximate Verification Procedures for Cross Laminated Timber. Institute for Timber Engineering and Wood Technology Management. Research Report, Holzbau Forschungs gmbh, Graz, Austria, 2012. 
[27] Harte A, McPolin D, Sikora K, O'Neill C, O'Ceallaigh C. Irish timber - characterisation, potential and innovation. Proceedings of Civil Engineering Research in Ireland, Belfast, 2014, p. 63-68.

[28] Franke $S$, Franke B, Harte AM. Failure modes and reinforcement techniques for timber beamsState of the art. Construction and Building Materials, 97, 2015 p. 2-13.

[29] Raftery GM, Harte AM. Material characterisation of fast-grown plantation spruce. Proceedings of the ICE-Structures and Buildings 167 (6), 2013, p. 380-386.

[30] Harte AM, Baylor G. Structural evaluation of castellated timber I-joists. Engineering Structures, 33(12), 2011, p. 3748-54.

[31] Raftery GM, Harte AM. Low-grade glued laminated timber reinforced with FRP plate. Composites Part B: Engineering, 42(4), 2011, p. 724-735.

[32] Raftery GM, Harte AM, Rodd PD. Bonding of FRP materials to wood using thin epoxy gluelines. International Journal of Adhesion and Adhesives 29(5), 2009 p. 580-588.

[33]Raftery GM, Harte AM, Rodd PD. Bond quality at the FRP-wood interface using wood-laminating adhesives. International Journal of Adhesion and Adhesives, 29 (2), 2009, p. 101-10.

[34] Raftery G, Harte A, Rodd P. Qualification of wood adhesives for structural softwood glulam with large juvenile wood content. Journal of the Institute of Wood Science, 18 (1), 2008, p. 24-34.

[35] Bahadori-Jahromi A, Zhang B, Harte A, Walford B, Bayne K, Turner J. Investigating the structural performance of multi-webs I-beams. Journal of the Institute of Wood Science, 17(3), 2006, p. 148-58.

[36] Bahadori-Jahromi A, Kermani A, Zhang B, Harte AM, Bayne K, Turner J, Walford B. Influence of cross-section on the strength of timber beams. Proceedings of the ICE-Structures and Buildings, 159(2), 2006, p. 103-14.

[37] Crawford D, Hairstans R, Smith RE. Feasibility of cross-laminated timber production from UK Sitka spruce. ECOST-MEETING-FP1004-210513-028873, ISBN 185790181 9, 2013, p. 37-52.

[38] Sikora KS, McPolin D, Harte AM. Shear strength and durability testing of adhesive bonds in cross-laminated timber. The Journal of Adhesion. DOI: 10.1080/00218464.2015.1094391, 2015.

[39] prEN 16351:2013. Timber structures - Cross laminated timber - Requirements, CEN, 2013.

[40] EN 384:2010. Structural timber - Determination of characteristic values of mechanical properties and density, CEN, 2010.

[41] EN 408:2010+A1:2012. Timber structures - Structural timber and glued laminated timber Determination of some physical and mechanical properties, CEN, 2012.

[42] EN-338:2009 Structural timber - Strength classes, CEN (2009).

[43] Ridley-Ellis D, Moore J, Khokhar AM. Random acts of elasticity: MoE, G and EN408. WG meetings COST Action E53 "Quality Control for Wood and Wood Products" and Wood Drying Seminar, Bled, Slovenia, 2009. 